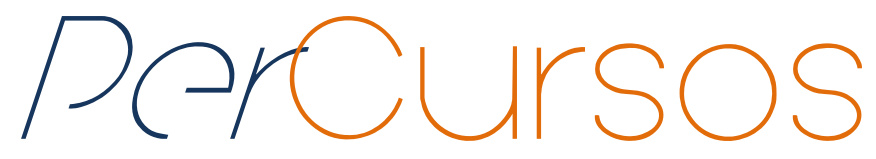

\title{
Uma experiência do PIBID - História da UFRJ: cinema com história na escola ${ }^{1}$
}

\begin{abstract}
Resumo
O presente artigo pretende apresentar e descrever a realização, impactos e resultados da atividade denominada CineHist, realizada no âmbito do subprojeto de História da Universidade Federal do Rio de Janeiro - UFRJ, no Ciep 205 - Frei Agostinho Fincias, localizado na zona norte da cidade do Rio de Janeiro. Analisaremos, também, a importância do uso de novas fontes, como o cinema, no processo de ensino-aprendizagem. A metodologia que utilizamos é o uso de filmes para a compreensão e interpretação da cidade do Rio de Janeiro, apresentando assim a atividade realizada com estudantes da educação básica. Além disso, torna-se central uma análise, ainda que breve, da importância do Programa Institucional de Bolsas de Iniciação à Docência - PIBID para a formação inicial e continuada de profissionais da educação. Além de promover a aproximação entre as escolas e as universidades, e a teoria e a prática, o programa também promove uma formação inserida no fazer docente que contribui para a melhoria do ensino básico e dos cursos de formação de professores no país.
\end{abstract}

Palavras-chave: Cinema; Ensino de História; PIBID.

\author{
Rafaela Albergaria Mello \\ Mestre em Práticas de Educação \\ Básica pelo Colégio Pedro II. \\ Professora de História da \\ Secretaria de educação do \\ estado do Rio de Janeiro. \\ Brasil \\ rafaelalbergaria@gmail.com
}

\section{Cinthia Monteiro de Araujo \\ Doutora em Educação pela}

Pontifícia Universidade Católica do Rio de Janeiro - PUC-Rio.

Professora da Universidade

Federal do Rio de Janeiro - UFRJ. Brasil

cinthiaraujo@hotmail.com

Livia Mourinõ de Mello

Graduada em História pela UFRJ.

Tutora de História no CEDERJ.

Brasil

liviamourino@gmail.com

\section{Kevin de Araujo Dias}

Graduando em História na UFRJ.

Brasil

kevinaraujo.kd@gmail.com

\footnotetext{
1 Subprojeto PIBID História UFRJ, vinculado ao projeto PIBID UFRJ, com apoio da Coordenação de Aperfeiçoamento de Pessoal de Nível Superior - CAPES.
} 


\title{
A PIBID experience - History UFRJ: history within movies in the school
}

\begin{abstract}
This present article intends to present the ministering, impacts and results of the activity denominated CineHist, which took place under the History subproject of Universidade Federal do Rio de Janeiro - UFRJ, at Ciep 205 - Frei Agostinho Fincias, located at Rio de Janeiro north district. We shall analyze as well the importance of the use of new sources, such as cinema, in the process of teaching-learning. The methodology we use is the use of films for the understanding and interpretation of the city of Rio de Janeiro, thus presenting the activity carried out with students of basic education. Additionally, it becomes central, even though short, an analysis of the importance of the Programa Institucional de Bolsas de Iniciação à Docência - PIBID both for the initial and continuous training of education professionals and for bringing closer schools, universities and theory and practice when promoting a learning to teach.
\end{abstract}

Keywords: Movie; History Teaching; PIBID.

\section{Para citar este artigo:}

MELLO, Rafaela Albergaria; ARAUJO, Cinthia Monteiro de; MELLO, Livia Mourinõ de; DIAS, Kevin de Araujo. Uma experiência do PIBID - História da UFRJ: cinema com história na escola. Revista Percursos, Florianópolis, v. 17, n.35, p. 96 - 121, set./dez. 2016.

\section{DOI: $\mathbf{1 0 . 5 9 6 5 / 1 9 8 4 7 2 4 6 1 7 3 5 2 0 1 6 0 9 6}$}

http://dx.doi.org/10.5965/1984724617352016096 


\section{Introdução}

Segundo o estudioso em educação Antônio Nóvoa (2010), existe um consenso discursivo quanto aos princípios necessários à formação docente. Entretanto, as licenciaturas são deficitárias e é difícil encontramos esses princípios nos cursos de formação de professores. Para Nóvoa, cinco são as disposições necessárias à prática docente: o tacto pedagógico, o trabalho em equipe, o compromisso social, a cultura profissional e o conhecimento. Porém, é na construção de uma dessas disposições, a cultura profissional, que identificamos a principal falha dos cursos de licenciatura e a ausência dos princípios básicos aos profissionais da educação.

A cultura profissional é um princípio que diz respeito à compreensão dos sentidos da instituição escolar e a integração à profissão. Para ele, essa disposição, em particular, só pode se realizar dentro da escola e em contato com profissionais já atuantes em sala de aula. O autor não nega a centralidade do conhecimento no processo de ensinoaprendizagem; não apenas conhecer o que se vai ensinar, mas a quem vai ensinar; entretanto, afirma que é no "chão da escola" que se aprende a dar aula, que se aprende a transformar o conhecimento acadêmico em conhecimento escolar.

Acreditamos que o processo de ensino-aprendizagem é um processo dialógico e construído na troca entre os atores e, portanto, só pode se realizar plenamente no local onde esses indivíduos interagem. "É na escola e no diálogo com os outros professores que se aprende a profissão" (Nóvoa, 2010, p. 3).

Nesse sentido, ao destacar a importância da interação entre o conhecimento e a formação da cultura profissional na formação de professores, o autor trata de dois importantes temas para a área: a formação inserida no fazer docente e a relação entre a teoria e a prática.

Os estudos de Nóvoa, assim como de Gatti e Nunes (2009), apontam que uma das principais falhas das escolas de formação de professores no país é, justamente, o distanciamento entre a escola e a universidade. Esse abismo impede uma formação construída dentro da profissão e a construção de uma relação dialógica entre a teoria e a prática. 
Com base nesses estudos, o Ministério da Educação e Cultura - MEC, através das suas agências responsáveis pelo ensino básico e valorização do magistério, tem buscado iniciativas que corrijam os erros apontados por esses estudiosos e proporcionem uma formação docente plena. Entre os programas criados, destaca-se o Programa Institucional de Bolsas de Iniciação à Docência - PIBID, iniciado em 2007.

Esse programa, implementado em âmbito nacional, tem como objetivo principal funcionar como um programa de formação inicial interligando as Instituições de Ensino Superior - IES às escolas da rede básica dos estados onde atuam. A proposta do programa é inserir os alunos licenciandos no ambiente escolar sob a supervisão dos professores das escolas e da coordenação dos professores das licenciaturas.

O presente artigo refere-se a uma das atividades pedagógicas realizadas no âmbito do subprograma de História que integra o PIBID da Universidade Federal do Rio de Janeiro, no ano de 2015, no Ciep 205 - Frei Agostinho Fincias, localizado na região da comunidade São João, no subúrbio carioca do Engenho Novo - Rio de Janeiro.

Em todo o país, os subprogramas que integram o projeto do PIBID possuem bastante autonomia na maneira como agem nas escolas selecionadas. O critério básico é que sigam os valores e objetivos do projeto previsto nos editais, mas que possam ter liberdade de atuação. Essa autonomia justifica-se pela pluralidade e diversidade dos contextos e locais das escolas e IES, pois a limitação nas formas de atuação dos programas incorreria no equívoco de desrespeitar as necessidades e particularidades regionais.

Além disso, a uniformização das atividades faria do PIBID um programa de experiências das universidades nas escolas, o que contradiz os princípios educacionais que orientam o projeto. A ideia é que as atividades sejam planejadas levando em consideração a realidade das escolas e as demandas locais, respeitando a cultura escolar e enxergando o espaço escolar como espaço de formação e experiência dialogado.

O subprojeto de história da UFRJ, denominado História para que te quero História, busca atender aos objetivos do projeto através da proposta de realização de atividades pedagógicas nas escolas, antecedidos de discussão teórica e planejamento das mesmas. 
Entre as propostas práticas descritas no subprojeto, duas preveem a utilização de cinema como metodologia de ensino: História no cinema, que propõe a organização de ciclos de debate sobre temas históricos e Cinema na escola, que objetiva a produção de vídeos de curta duração pelos alunos.

A atividade que será analisada no presente trabalho, denominada CineHist, teve como objetivo unir as duas propostas pedagógicas ao conteúdo estudado pelos alunos nas aulas de história. Soma-se a isso, o aniversário de 450 anos da cidade do Rio de Janeiro, completados no ano de 2015.

A metodologia utilizada foi a análise fílmica proposta por Kossoy (2001), em que afirma que através da capacitação de uma imagem fotográfica, podemos vivenciar o registro de um tempo, aspectos da habitação, dos costumes, religião e acontecimentos sociais de modo geral. A análise das imagens é o fio condutor de uma época através das lentes de um artista, no nosso caso, dos filmes.

A utilização de fontes como filmes é uma forma de abordar a temática dos 450 anos da cidade do Rio de Janeiro de maneira atraente aos estudantes. Nosso objetivo foi o de empregar recursos disponíveis para despertar o interesse e a curiosidade dos estudantes sobre os assuntos abordados e as aulas de história.

Vivemos em uma época da modernidade, da velocidade da informação, da comunicação, da publicização de imagens sobre temas diversos em todos os lugares, do acesso aos quatro cantos do planeta através das redes midiáticas e, particularmente, pela internet. Por isso, esse é mais um fator que, para nós, torna imprescindível e necessária a utilização de imagens nos conteúdos do ensino de história. Não imagens meramente ilustrativas, mas para as problematizações como fontes históricas.

Pretendemos aqui, através da análise, descrição e resultados da atividade CineHist, refletir sobre a importância do PIBID para o processo de formação de professores ao possibilitar uma formação que contemple a interação entre os debates teóricos e a prática docente, além de incentivar o diálogo, na prática cotidiana, entre os diversos atores que o compõem. 


\section{O Programa Institucional de Bolsas de Iniciação à Docência - PIBID}

A relação entre a teoria e a prática docente constitui-se, nos dias atuais, como um dos principais temas na área de estudos em educação e ensino. É a partir dela que emergem outras questões importantes para esse campo de conhecimento como: a relação entre a escola e a universidade, e a formação do licenciando inserida no fazer docente.

Segundo estudo avaliativo do PIBID, publicado em setembro de 2014, a emergência de políticas públicas de fomento à educação e incentivo a melhorias nos cursos de licenciatura, tanto no âmbito federal, quanto no estadual e municipal, tem como base as críticas feitas aos currículos dos cursos de formação de professores, principalmente no que diz respeito à relação entre teoria-prática e o distanciamento entre os espaços de formação acadêmica e experiência docente (GATTI, 2014).

Baseado nas pesquisas de Gatti e Nunes (2009), o estudo indica que os cursos de licenciatura no Brasil são deficitários, pois não vêm oferecendo as habilidades e os conhecimentos necessários à formação docente, o que tem posto em questão o papel das universidades nesse processo. Segundo o documento

[...] os cursos mantêm-se focados em modelos idealizados de aluno e de professor, com predominância dos estudos teóricos e das disciplinas de formação genérica em relação à formação para a prática docente. A relação teoria-prática é quase ausente nas dinâmicas curriculares, bem como estudos sobre a escola, o que indica uma formação de caráter abstrato e desarticulada do contexto de atuação do professor. (GATTI, ANDRE, GIMENES, FERRAGUT, 2014, pp. 13-14)

Tendo como base as análises acerca das deficiências nos cursos de formação de professores, e como isso tem influenciado o ensino na rede básica, a CAPES Coordenação de Aperfeiçoamento de Pessoal de Nível Superior criou dois órgãos internos: a Diretoria de Educação a Distância - DED e a Diretoria de Educação Básica Presencial - DEB. Nesse contexto, coube à DEB a responsabilidade de planejar e gerenciar os projetos presenciais de valorização do magistério da CAPES. 
Em 2 de março de 2012, através do decreto $n^{0}$ 7.692, a diretoria teve o nome alterado para Diretoria de Formação de Professores da Educação Básica, mantendo a sigla DEB, já consolidada na CAPES e nas instituições parceiras. A mudança de nome não alterou a função do órgão, mas possibilitou evidenciar com mais clareza sua missão: estimular o reconhecimento da prática docente através da formação qualificada de profissionais da educação.

Os esforços demandados na implementação dessa missão justificam-se pelo fato de que, na visão da CAPES e da DEB, a valorização da educação - professores, instituições formadoras e o próprio ensino básico -, é um fator fundamental, ainda que não único, para a construção e consolidação de um país democrático, socialmente inclusivo e economicamente desenvolvido. A concretização desse projeto é resultado

[...] de uma política de Estado que atraia novos profissionais, mantenha na rede os já atuantes e assegure o reconhecimento da sociedade ao trabalho docente. Essa política envolve plano de carreira, salário digno, formação inicial e continuada articulada à progressão funcional, boas condições físicas e tecnológicas nas escolas, clima organizacional que motive professores e alunos para o ensino e a aprendizagem, jornada de trabalho integral e, ainda, gestão escolar comprometida com o sucesso escolar de todos. (GATTI, ANDRÉ, GIMENES, FERRAGUT, 2014, p. 04)

Nesse sentido, em 2007, foi iniciado o Programa Institucional de Bolsas de Iniciação à Docência (PIBID), que é um dos três programas da DEB que se inserem na linha de ação para formação inicial. Mais que um programa de bolsas, objetiva atender os princípios e compromissos da Capes com a valorização da docência através da formação qualificada de professores e promover o incentivo a uma formação inserida no fazer docente.

Tendo como base os estudos de Nóvoa (2009) sobre a formação de professores, o programa tem como princípio a elaboração e consolidação de uma nova cultura 
educacional. Segundo Relatório de Gestão 2009-2013 da Capes², essa nova cultura educacional estrutura-se nos seguintes pontos:

1. formação de professores referenciada no trabalho na escola e na vivência de casos concretos;

2. formação de professores realizada com a combinação do conhecimento teórico e metodológico dos professores das instituições de ensino superior e o conhecimento prático e vivencial dos professores das escolas públicas;

3. formação de professores atenta às múltiplas facetas do cotidiano da escola e à investigação e à pesquisa que levem à resolução de situações e à inovação na educação;

4. formação de professores realizada com diálogo e trabalho coletivo, realçando a responsabilidade social da profissão.

Notamos que os princípios que norteiam a constituição dessa nova cultura educacional levam em consideração a escola como espaço de experiência, diversidade e diálogo, a relação entre teoria-prática, universidade-escola e formadores-formandos e a responsabilidade social presente na docência. Assim, o programa pretende orientar uma formação que integre saberes de todos os agentes envolvidos: licenciandos, professores da rede básica e professores das Instituições de Ensino Superior - IES.

A proposta é impulsionar uma formação em que os agentes tornem-se protagonistas no processo tanto nas escolhas das ações, quanto nas escolhas do referencial teórico-metodológico para que possam dar suporte a essa rede formativa. Nessa linha, a ideia é que a formação seja pautada em um pensamento reflexivo-crítico, e, não mais, em uma formação instrumentalizante e técnica para a prática docente.

O PIBID oferece bolsas a alunos de cursos de licenciaturas para que exerçam atividades pedagógicas em escolas de ensino básico. Para supervisionar e auxiliar o trabalho dos bolsistas ID - iniciação à docência / graduandos -, o programa também

\footnotetext{
${ }^{2}$ BRASIL, Ministério da Educação, coordenação de aperfeiçoamento de Pessoal de Nível Superior, Diretoria de Formação de Professores da Educação Básica, Relatório de Gestão PIBID 2009-2013. Brasília, 2013. Brasil.
} 
concede bolsas aos professores das licenciaturas - coordenadores de área - e aos professores das escolas públicas de ensino básico - supervisores.

O programa de iniciação à docência foi desenvolvido inicialmente nas áreas consideradas pela DEB com carência de docentes: física, química, biologia e matemática. Entretanto, a partir da verificação dos primeiros resultados positivos e o crescimento do interesse, em 2009, o projeto foi ampliado para todas as disciplinas da educação básica, incluindo, a partir de então, a disciplina de História, além da educação de jovens, o ensino para adultos, indígenas, quilombolas e moradores do campo.

No campo da História, segundo números do Relatório de Gestão do PIBID³, das 313 IES que integram o projeto no país, 128 possuem subprojetos de História. Já no estado do Rio de Janeiro, 19 IES abrigam o PIBID, sendo nove na área de História. São elas: Escola Superior de Ciências Sociais / Fundação Getúlio Vargas (FGV), Faculdades Integradas Campo-Grandenses (FIC), Pontifícia Universidade Católica do Rio de Janeiro (PUC - RJ), Universidade do Estado do Rio de Janeiro (UERJ), Universidade Federal Fluminense (UFF), Universidade Federal do Rio de Janeiro (UFRJ), Universidade Federal Rural do Rio de Janeiro (UFRRJ), Centro Universitário Geraldo Di Biase (UGB) e ABEU - Centro Universitário (UNIABEU).

Juntas, as nove IES somam 12 subprojetos ${ }^{4}$, nove bolsas de Coordenação Institucional (Cl), 23 de Coordenação de Área (CA), 63 de Supervisão (S) e 344 bolsas de Iniciação à Docência (ID).

\section{O CIEP 205 Frei Agostinho Fincias e o PIBID}

O CIEP 205 - Frei Agostinho Fincias está localizado na região da comunidade São João no subúrbio carioca do Engenho Novo. Apesar da ideia comum de que os CIEPS são

\footnotetext{
${ }^{3}$ BRASIL, Ministério da Educação, coordenação de aperfeiçoamento de Pessoal de Nível Superior, Diretoria de Formação de Professores da Educação Básica, Relatório de Gestão PIBID 2009-2013. Brasília, 2013. Brasil.

${ }^{4}$ Algumas IES possuem mais de um subprojeto na área de História devido à existência de mais de um campus lecionando o curso. É o caso de UFF: subprojetos em Niterói e Campos dos Goytacazes; UERJ: subprojetos no Rio de Janeiro e São Gonçalo e UFRRJ: subprojetos em Seropédica e Nova Iguaçu.
} 
iguais, percebemos que cada um traz especificidades que estão relacionadas, principalmente, com a localidade onde estão inseridos.

Fazendo uma breve análise do contexto no qual o CIEP se insere, destacamos que duas são as principais particularidades. A primeira diz respeito à violência urbana do local. Localizado em uma região de divisa entre comunidades, observamos que era recorrente a interrupção das aulas em função de tiroteios entre facções criminosas e operações da polícia militar. Outra questão pertinente é que o bairro do Engenho Novo também não oferece opções de lazer como shoppings, praças espaçosas, cinemas ou teatros.

Assim, destacamos uma primeira importância que justifica a presença do programa nas escolas públicas em todo território brasileiro. Consideramos que as atividades que o PIBID implementa nesses espaços escolares são atividades voltadas para o processo de ensino-aprendizagem, mas também são atividades lúdicas e criativas que movimentam o cotidiano das escolas e o dia a dia dos atores envolvidos.

O público do CIEP 205 é formado por jovens das comunidades próximas à escola como Morro do Encontro, Morro do São João e Complexo do Lins. Boa parte dos estudantes são jovens trabalhadores, muitos integrantes do programa do governo federal, Jovem Aprendiz. Ao lado desse primeiro grupo, também há uma pequena parcela de jovens que ainda não estão inseridos no mercado de trabalho e, por isso, muitas vezes ficam ociosos no contraturno da escola.

O PIBID História da UFRJ foi inserido na realidade do CIEP 205 no ano de 2014, sob a supervisão da professora Rafaela Albergaria. Durante os anos letivos de 2014 e 2015, a escola recebeu cinco bolsistas de iniciação à docência com o objetivo de criar e realizar atividades na escola. A partir de então, a escola assumiu o papel de espaço de experiência e de formação ao integrar estudantes da educação básica, professores de rede pública e estudantes de licenciatura.

O diálogo construído entre esses atores, além de contribuir para a formação inicial e continuada da professora supervisora e dos bolsistas ID, também contribuiu para a formação dos alunos ao, por meio das atividades realizadas, possibilitar o desenvolvimento de maior senso crítico, participação e interesse nas aulas e na escola. 
As atividades realizadas pelo PIBID, ao longo desses dois anos, ocorreram tanto no turno da manhã como no da tarde para todo o ensino médio, abrangendo assim o maior número de estudantes possíveis. Com a intenção de atender os alunos que não estavam em aula, a realização de atividades no contraturno dos estudantes forneceu também uma opção cultural, permitindo que esses ficassem mais tempo na escola e evitando um grande período ocioso ao longo da semana.

\section{O uso de novas fontes no campo da História}

Ao utilizar o cinema para a análise de determinados fatos históricos, levamos ao espaço escolar uma ferramenta que consideramos importante: o uso de filmes. Através dessa fonte e da metodologia adotada, buscamos articular os conhecimentos já existentes dos estudantes aos conhecimentos das aulas prévias e isso, aos conhecimentos trazidos pelos filmes objetivando a construção de novos saberes.

As imagens visuais estão tendo cada vez mais espaço no regime de historicidade contemporânea. Mas esse não foi um caminho fácil. A partir da década de 60, a imagem começou a ser utilizada como fonte visual, mas, para isso, a História passou por um longo processo de 'amadurecimento'. Até então, as pesquisas no campo da História não consideravam como fonte documentos que não fossem escritos. Além disso, o uso das imagens, até então, era feito apenas para ilustração, sem dar uma vida social, contextualização e crítica. Apesar dos avanços na aceitação do uso de fontes não escritas, ainda existe receio em dar lugar à cultura visual.

Os historiadores Ciro Flamarion e Ana Maria Mauad, no artigo História e Imagem: os exemplos da fotografia e do cinema (1997), destacam que a imagem é a materialização da experiência vivida. Uma realidade que foi formulada a partir do trabalho de outros homens, um trabalho cultural, mas que quis e pretendeu retratar determinados acontecimentos na frente de outros.

O historiador Paulo Knauss, em seu artigo (2006), afirma que a valorização das imagens como fontes de pesquisa virá através do estudo da cultura visual aliada à história da arte, estabelecendo assim um plano metodológico interdisciplinar para os estudos 
visuais. Para isso, ainda existe a necessidade da conceituação da arte como sendo histórica e, portanto, as imagens ainda são reféns da cultura pré-estabelecida em que se encontra inserida.

Para definir a cultura visual, segundo o autor, é necessário abordá-la em duas perspectivas: uma restrita, que se adequa a uma necessidade da cultura ocidental científica para afirmar o domínio tecnológico dos tempos atuais e, outra, abrangente, que auxilia para pensar experiências visuais em tempos e sociedades distintas.

Ulpiano Meneses é categórico ao afirmar o atraso da História como disciplina quando comparada a outras ciências humanas. Segundo o autor, esse atraso se dá não apenas em relação às fontes visuais, mas também, à problemática básica da visualidade (MENESES, 2003). Isso equivaleria a dizer que ainda não há uma tendência à produção de conhecimento histórico novo a partir das fontes visuais, e sim a de trabalhar a fonte visual como informação histórica externa às imagens. Consequentemente, a função da imagem ainda fica ligada majoritariamente como ilustração afirmativa, sem peso na pesquisa, usada somente a partir de outras fontes, delimitando a sua função á indução estética em reforço ao texto.

François Hartog (1996) nos mostra as variações diversas dos regimes de historicidade que organizam o passado como uma sequência de estruturas até os dias de hoje, em que passamos de um futurismo para um presente hipertrofiado. Assim, o ponto de vista que prevalece é unicamente o do presente, o que torna a pesquisa uma ferramenta de previsão do futuro, sem deslocar-se do presente. A produção tecnológica acelera-se de tal forma que se busca por uma memória identitária. $\mathrm{O}$ autor ressalva que a história do presente não é tão segura quanto nos parece ser e o historiador deve identificar o seu ponto de vista através de uma abordagem comparativa que ofereça uma resposta possível.

Para trabalhar com imagens, Meneses (2003) propõe algumas premissas para a consideração de uma história visual que, para ele, seria um conjunto de recursos operacionais capazes de ampliar a pesquisa histórica. Ele vai relatar que, na Antiguidade e na Idade Média, o uso da imagem era religioso e não havia traços de uso político. Desde o 
Renascimento, há um esforço para organizar as imagens e decodificar seus significados. Somente a partir do XIX serão aceitas as fontes iconográficas no domínio da história da arte e, tempos depois, na história Cultural.

Dois movimentos vão surgir, um à procura da criação artística, buscando pela antropologia, e outro, atrás da marca documental classificatória. As imagens são novos horizontes documentais e através deles o historiador pode ter um novo padrão de análise social. O objetivo do estudo do historiador através das imagens normalmente são as sociedades, pois este é o objeto de estudo do historiador. O emprego da imagem como fonte é apenas um dos tantos recursos que podem ser utilizados, como também a história oral. É preciso promover pesquisas para que a história avance e não fique à margem como no período cientificista, no qual as ciências humanas já buscavam interpretar as imagens como sujeitos e, para a História, ainda era apenas usada como estilo estético.

Em outro artigo seu, Meneses (2005) apresenta as recentes publicações que buscam teorizar sobre o uso de imagens como fontes, procurando mostrar como se desenvolvem as relações das fontes visuais com o historiador e o surgimento do crescente despertar dos problemas visuais. "A imagem esta reivindicando seu próprio modo de análise". Para Meneses, são três os pré-requisitos para que a história trabalhe com fontes visuais: o visual, o visível e a visão que, juntos, procuram a criação de um quadro de informação, problemas e instrumentos conceituais e operacionais relativos às questões. Sem esses pontos, não há uma sustentação sólida.

Dessa forma, acreditamos que inserir o uso do cinema para a história é uma ferramenta importante e que tem uma base teórica importante, inclusive de luta.

\section{O cinema na sala de aula: O CineHist}

No ano de 2015, a cidade do Rio de Janeiro completou 450 anos e a equipe de bolsistas atuantes no CIEP 205 elegeu esse como um bom mote para a realização de uma oficina de cinema, já prevista no subprojeto de História da UFRJ. Para que a atividade tivesse coerência com as aulas, aguardamos que o conteúdo das turmas da professora 
supervisora chegasse à análise do período da Primeira República (1889-1930) quando, através de temas como a Reforma Pereira Passos e a Revolta da Vacina, por exemplo, a cidade do Rio ganha centralidade nas análises históricas.

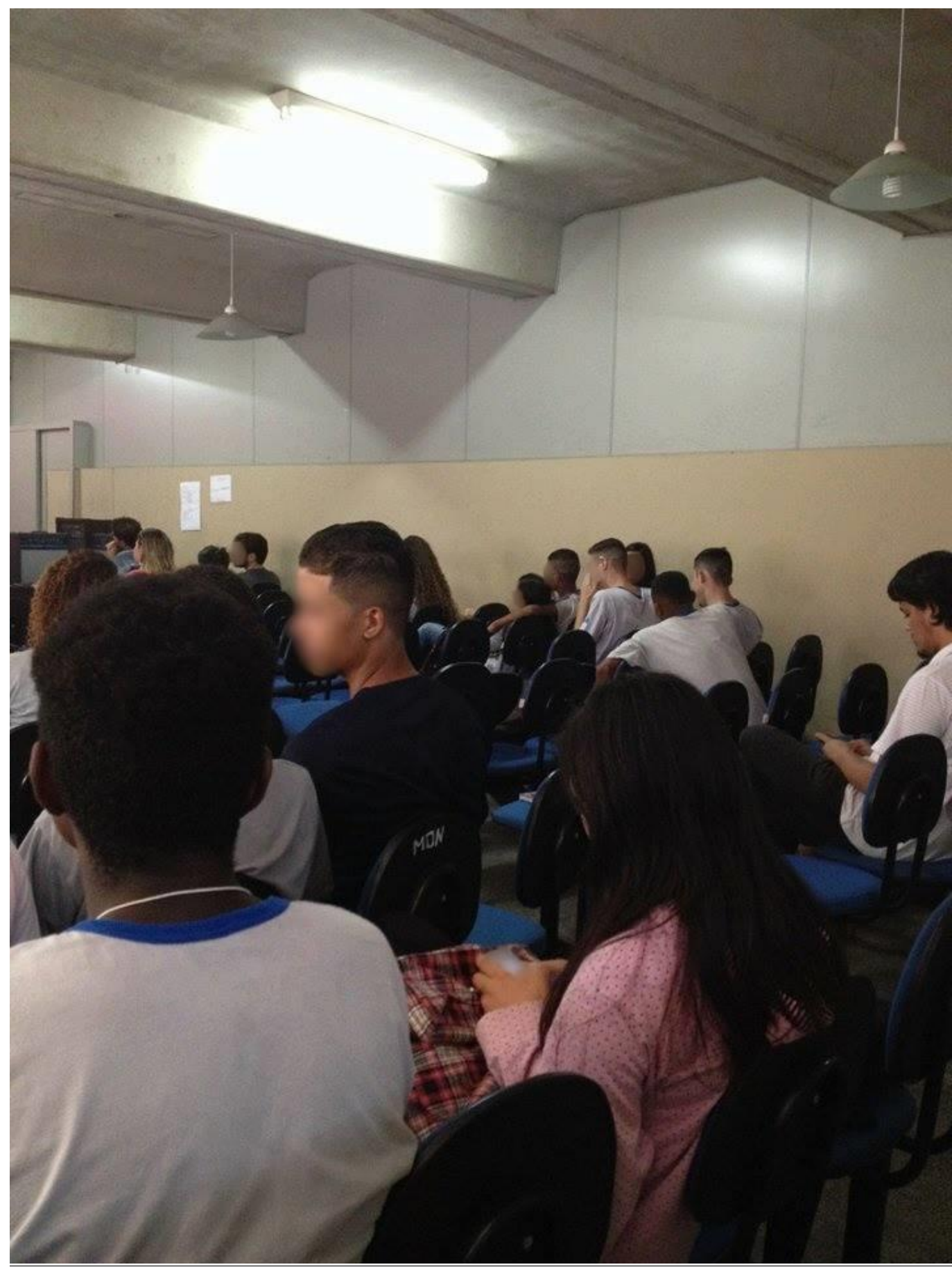

Figura 1- Alunos durante a exibição do filme. Fonte: Acervo PIBID História UFRJ, 2015. 
Uma grande preocupação da equipe era não entrar no ufanismo das comemorações e sim, realizar uma atividade pedagógica reflexiva e crítica por intermédio do uso do cinema para que os estudantes analisassem e compreendessem em diversas dimensões a cidade em que vivem. O cinema é uma importante forma de comunicação e pode ser utilizado como meio para que o ensino e a aprendizagem aconteçam de forma mais lúdica. Por isso, acreditamos no uso do cinema como uma ferramenta importante no ensino de história dentro e fora da sala de aula.

A atividade realizada foi denominada CineHist e ocorreu em três sessões semanais com temáticas diferentes sobre a cidade do Rio de Janeiro. Nosso objetivo foi possibilitar aos estudantes, por meio da análise dos processos históricos já mencionados e pelo uso de uma nova fonte, novas formas de pensar a cidade e como eles se relacionam e experimentam o local onde moram.

Buscamos em nossas atividades implementar os princípios e objetivos gerais do projeto entendendo que são centrais para a formação inicial e continuada dos agentes envolvidos. Nesse sentido, antes de iniciar o ciclo de filme e debates com os alunos dimensão prática da atividade -, procuramos aprofundar a parte teórica. Elegemos uma linha teórica e uma metodológica a serem estudadas pelos bolsistas envolvidos antes da implementação do CineHist: no campo teórico, buscamos autores que refletissem sobre a cidade do Rio de Janeiro e suas transformações desde o início do século XX até os dias atuais e, no campo metodológico, autores que debatessem o uso de documentos não escritos como fonte, tanto na pesquisa histórica, quando no ensino dessa disciplina.

As sessões foram realizadas no auditório da instituição no horário da tarde e de forma aberta a todos os alunos do ensino médio. Para os alunos que se encontravam em horário de aula, pedimos aos professores que fossem liberados, tendo em vista a importância do tema e a contribuição para a formação dos alunos.

Durante os filmes, oferecemos um pequeno lanche com pipoca e suco. Nossa intenção era a de criar um ambiente mais confortável e familiar, deixando-os mais à vontade para participarem do debate, no qual eles teriam a oportunidade de se expressar e se posicionar sobre os temas abordados. 
A metodologia utilizada foi a proposta de análise fílmica de Menezes (2012), que afirma que há uma multiplicidade de significados e papéis que as imagens podem desempenhar. Dessa forma, consideramos que o cinema foi utilizado como uma fonte visual para que os estudantes refletissem questões acerca da cidade. Assim, procuramos através da análise dos filmes, seguida de debate, contextualizar e trazer um panorama do Rio de Janeiro desde o início do século XX até os dias atuais.

Os filmes que foram exibidos foram: $5 X$ Favela: Agora por nós mesmos, Sonhos Tropicais, e os curtas-metragens "Geral" e "A voz da arquibancada". Escolhemos esses três filmes com o tema transversal da cidade do Rio de Janeiro para abordar diferentes assuntos sobre a cidade, mas também nos orientamos por um critério central que foi o de trazer filmes e curtas que abordassem temas próximos do cotidiano desses alunos. Queríamos, sempre que possível, criar identificação e empatia dos alunos pelas fontes, fosse pelas histórias, pelos personagens ou pelos espaços geográficos utilizados nos filmes.

A primeira sessão foi realizada com o filme $5 x$ favela, agora por nós mesmos. Escolhemos iniciar o projeto com esse filme pois ele traz uma temática bastante próxima dos alunos. Na nossa observação, esse foi realmente um dos filmes que gerou mais participação, exatamente por conta da vivência dos alunos do colégio. O diálogo sobre o filme construiu, como esperado, um saudável espaço para discussão dos vários problemas atuais da cidade, principalmente aqueles concernentes com o espaço em que o filme se passava, as favelas cariocas. O enfoque dessa sessão foi justamente discutir as questões que envolviam o cotidiano da periferia da cidade do Rio de Janeiro e seus respectivos agentes históricos, ressaltando a importância do olhar sobre esses espaços e a inserção dos mesmos na dinâmica de mudança pela qual passa a cidade.

O filme 5X Favela - Agora por nós mesmos, foi lançado em 2010 e teve como diretores moradores das favelas cariocas. A película é uma releitura do filme "Cinco Vezes Favela", de 1962, um clássico do Cinema Novo. Assim como a versão original, o filme traz uma coletânea de cinco esquetes que procuram trazer à tona dinâmicas sociais próprias das favelas cariocas, mas, dessa vez, dirigidos pelos próprios moradores das comunidades. 
No primeiro título, chamado "Fonte de Renda", o personagem principal é um graduando de Direito e morador de uma das comunidades da cidade. Ele acaba enfrentando problemas financeiros para arcar com os custos da universidade e, para solucionar suas dívidas, recorre à venda de drogas para colegas estudantes. O esquete tem um final pouco elaborado, mas consegue trazer discussões importantes sobre a logística do tráfico na cidade, a importância da desigualdade social no debate do tema e a punição assimétrica empreendida pelos órgãos de repressão, que acaba punindo mais severamente as classes populares.

Logo em seguida, é apresentado outro curta chamado “Arroz com Feijão”. Ao ver seu pai cansado de levar para o trabalho a mesma marmita contendo somente arroz e feijão todos os dias, seu filho pede ajuda de um amigo para conseguir um frango e presenteá-lo em seu jantar de aniversário. Eles fazem de tudo para conseguir levantar algum dinheiro e enfrentam diversos obstáculos, como, por exemplo, o roubo que sofrem de "mauricinhos" quando estão próximos de conseguir a comida. A esquete é muito bem-humorada e traz à tona uma gama diversa de questões importantes para se pensar o cotidiano das favelas cariocas. Além do resgate da triste realidade material das populações pobres da cidade, ela também traça algumas linhas sobre a violência urbana e o preconceito de classe.

O terceiro curta é denominado "Concerto Para Violino". É o mais violento dos esquetes e recorre ao lugar-comum das narrativas sobre a violência nas favelas cariocas. Nele, aparecem elementos muito importantes para a discussão, como a relação de cooperação entre parte da polícia e as facções criminosas, importante elo no fornecimento de armas e eliminação de grupos rivais. Com isso, é possível fazer um debate mais qualificado sobre a violência na cidade, seus elementos cruciais e as possibilidades possíveis de combate.

Em seguida, aparece o curta chamado “Deixa Voar”, que apresenta a história de um jovem que tem que buscar sua pipa perdida em uma favela rival. O roteiro explora bem essa relação tensa e tênue vivida no cotidiano das favelas da cidade. Com ele, pudemos explorar a territorialização das favelas, seus efeitos no cotidiano dos alunos e da cidade. 
O último curta é chamado de "Acende a Luz". O mais bem-humorado de todos os esquetes, aparece com uma narrativa leve e cômica. Nele, os moradores de uma favela ficam sem luz na véspera do natal e, ao chegar o técnico da companhia de eletricidade, o fazem de refém até que se resolva o problema. O esquete fecha com suavidade o filme permitindo levantar questões sobre a situação dos serviços públicos na região das favelas e o descaso do poder público com essas regiões.

A segunda sessão tinha como tema principal as reformas urbanas e os movimentos sociais. Para essa discussão, assistimos ao filme Sonhos Tropicais, produzido no ano de 2001 e dirigido por André Sturm, que é uma ficção que procura apresentar o contexto das transformações urbanas do início do século XX na cidade do Rio de Janeiro.

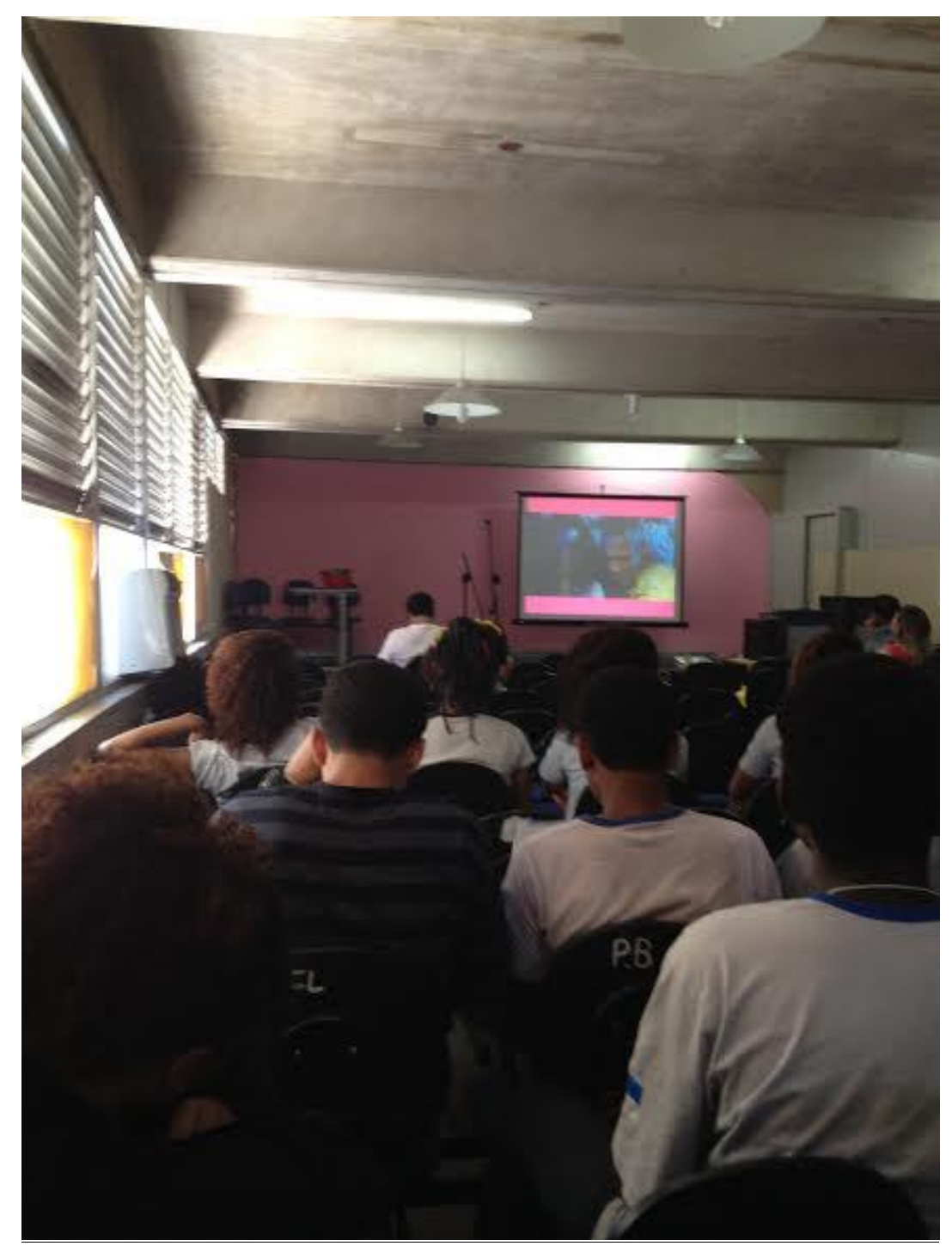

Figura 2 - Alunos durante a exibição do filme II. Fonte: Acervo PIBID História UFRJ,2015. 
O filme trabalha bem esse período, trazendo à tona uma gama muito grande de temáticas. Um dos pontos principais é o debate acerca da saúde pública e da política higienista focado na figura de Oswaldo Cruz, que aparece no filme como principal articulador das políticas públicas de saúde. A situação do Rio de Janeiro apresentada, no que concerne ao saneamento básico, é precária e isso é entendido como um dos principais vetores de doenças. Sendo assim, o governo carioca apresenta modelos de soluções, como a vacinação, que deveriam ser implementadas com a finalidade de resolver o problema das epidemias. Entretanto, as medidas são mal executadas, vinham em um momento de grande instabilidade política e detinham um caráter excludente. Por isso, enfrentaram uma forte resistência de grupos populares.

Ao mesmo tempo, a trama aborda a condição de vida dos imigrantes na cidade do Rio de Janeiro ao narrar a vida de Esther, uma jovem judia vinda da Polônia com uma promessa de casamento e que, ao chegar ao Rio de Janeiro, descobre que a promessa era um embuste e é obrigada a trabalhar como prostituta em um bordel da região da Lapa.

O filme faz um retrato minucioso do cenário carioca daquele momento, dando ênfase aos conflitos sociais existentes, à situação insalubre das massas, à exploração sexual, à imigração e às consequências das intervenções urbanas da política de Pereira Passos.

Um último objetivo que tínhamos com esse filme era, sempre preocupados em realizar as devidas localizações espaço-temporais e evitar anacronismos, o de estabelecer conexões entre a reforma empreendida no século XX e descrita pelo filme, Reforma Pereira Passos, e a atual reforma realizada na cidade, denominada Porto Maravilha, visando a modernização da região portuária para a recepção dos megaeventos internacionais: Copa do Mundo, 2014, e os Jogos Olímpicos, em 2015. Sendo assim, nosso intento nessa sessão era o de discutir as semelhanças e diferenças do histórico carioca de intervenções urbanas, dando enfoque ao caráter excludente de ambos os processos.

A terceira, e última, sessão tinha como tema a discussão de questões sobre a cidade através do espaço do futebol. Entendemos que, dada a importância desse esporte para o país e para os cariocas, ele pode ser compreendido como um microcosmo da 
sociedade através do qual podemos analisar os diversos temas importantes para o cotidiano da cidade.

Para esse debate, trouxemos dois curtas-metragens. O primeiro, chamado Geral, de aproximadamente 15 minutos, tinha como objetivo discutir como as mudanças ocorridas no principal palco do futebol carioca, o estádio Maracanã, refletem o fator excludente do projeto de reforma urbana implementado na cidade. Outro ponto dessa sessão, sendo a terceira e última, era estabelecer uma conexão com as anteriores.

O filme trabalha com os últimos dias da chamada geral do estádio - setor do estádio próximo ao gramado onde os preços eram baixos e, portanto, era uma área historicamente popular frequentada pelas classes trabalhadoras. Dessa forma, o espaço se constituiu ao longo de sua história como um ambiente de lazer e socialização dos torcedores populares, que criaram formas próprias e autênticas de torcer recebendo o apelido de "geraldinos". O curta, no formato de documentário, trazia entrevistas com esses torcedores e imagens da geral, que buscavam narrar as dinâmicas cotidianas desse setor, seus personagens e a sua atmosfera.

O filme termina expondo que esses espaços foram extintos com as reformas realizadas no estádio e que isso gerou uma profunda transformação na cultura do torcer. As reformas levaram ao encarecimento do preço dos ingressos, à elitização do público nas arenas e ao afastamento dos geraldinos dos estádios. A proposta foi problematizar o caráter elitista e excludente desses processos de transformação e adequação do estádio aos grandes eventos, que acabava por excluir grupos populares dos estádios devido à pequena capacidade e à carestia dos ingressos.

O segundo curta, chamado A voz da arquibancada, de produção do Núcleo de Audiovisual e Documentário CPDOC/FGV, aborda a temática do futebol carioca, entrevistando lideranças das torcidas organizadas dos principais times da cidade: Flamengo, Vasco, Fluminense e Botafogo. Entre os diversos temas debatidos no documentário, um dos focos é a questão da violência entre as torcidas jovens organizadas de futebol e qual a sua representação social para os integrantes desses grupamentos. Nosso objetivo era apresentar as mudanças e problemas característicos 
das torcidas organizadas cariocas, aqui elementos principais na festa das torcidas nas arquibancadas e, com isso, suscitar discussões sobre as mudanças ocorridas no cenário urbano carioca e a sua relação com os grandes eventos esportivos ocorridos de forma consecutiva na cidade.

Consideramos que as três sessões seguiam um eixo bastante especifico que propiciava o diálogo e a identificação dos alunos com os temas principais, a saber: a segregação espacial e a desigualdade social através de vários momentos e espaços distintos da cidade carioca, procurando estabelecer pontos de continuidade e ruptura. $\mathrm{O}$ objetivo, de maneira geral, era discutir questões relativas à cidade do Rio de Janeiro tendo como mote o aniversário da cidade e as transformações ocorridas nos últimos anos devido à realização de grandes eventos na cidade, como a Copa do Mundo de Futebol, em 2014, e os Jogos Olímpicos, em 2016.

Entendemos se tratar de importantes temáticas da cidade do Rio de Janeiro a serem discutidas com jovens em formação. Ao falarmos dos problemas sociais ocorridos em diversas favelas da cidade, os estudantes se identificaram em algumas situações, mas em outras, questionaram o conteúdo da ação do personagem na ficção, mostrando uma visão crítica acerca dos filmes e da realidade. No filme sobre as reformas urbanas e sobre a imigração para a cidade no início do século passado, os estudantes concluíram que, ainda hoje, são as camadas mais pobres que sofrem com as reformas urbanas por se tratarem de processos excludentes. Já no filme sobre o futebol, os alunos demonstraram empatia pelas rivalidades cariocas em cena e um forte saudosismo pelo estádio antes das reformas. 


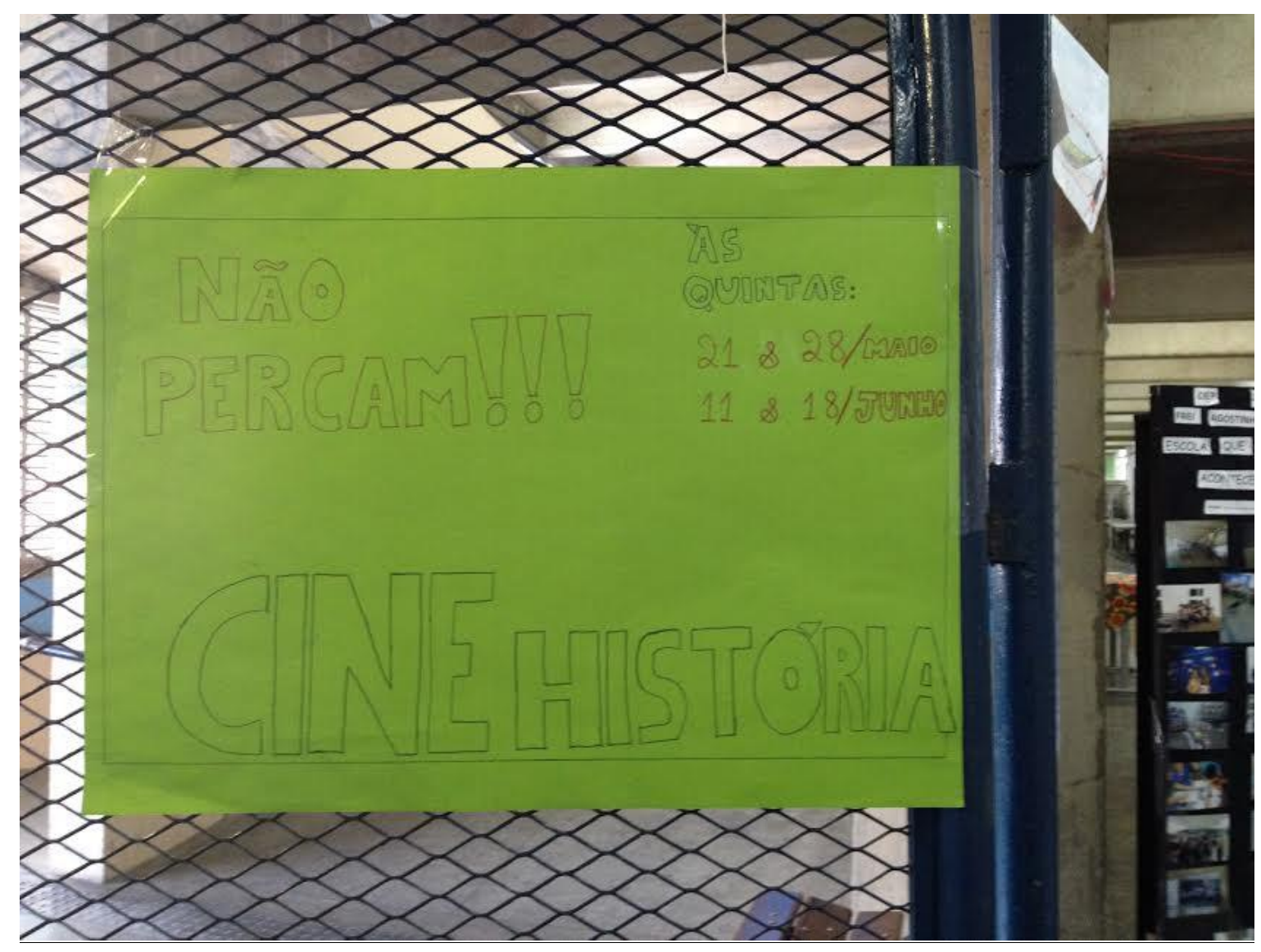

Figura 3 - Cartaz de divulgação do cinehist. Fonte: Acervo PIBID História UFRJ, 2015.

Destacamos que, no projeto inicial da oficina, pretendíamos concluí-la com uma atividade na qual os alunos produziriam um curta sobre a cidade do Rio. O tema era livre e a proposta era que gravassem com suas próprias ferramentas, como smartphones, após uma breve orientação sobre edição de filmes, e apresentassem em uma sessão aberta para toda a comunidade escolar. Porém, não foi possível realizar o plano final da atividade devido ao início da greve nas universidades federais e, por isso, optamos por fazer uma roda de conversa com os alunos participantes.

Em resumo, o CineHist foi uma atividade do subprojeto PIBID História - UFRJ, em que, de forma lúdica, utilizamos o cinema para promover o diálogo do uso dessa fonte para a compreensão da história da cidade do Rio de Janeiro a partir do gancho do aniversário da cidade, em uma perspectiva crítica e reflexiva, buscando a aproximação com a realidade da cidade que esses estudantes vivenciam. 


\section{Conclusão}

Consideramos que a atividade descrita e analisada no presente artigo é bastante significativa, pois sintetiza os objetivos do subprojeto de História na UFRJ: realizar atividades pedagógicas que estimulem a participação e o interesse dos alunos a partir do cumprimento dos objetivos gerais do projeto previsto em edital. Assim, planejamos o CineHist tendo como norte a relação dialógica entre a teoria e a prática, a aproximação entre os espaços de formação de professores e a escola básica, uma atividade que proporcionasse formação inicial e continuada para os agentes envolvidos e a inserção dos bolsistas de iniciação à docência no contexto escolar.

Compreendemos que a atividade atingiu nossas expectativas ao relacionar e concretizar todos os objetivos propostos. A etapa de seleção, leitura e debate de textos e materiais sobre os temas teóricos e metodológicos a serem implementados na atividade, além da análise dos filmes antes da utilização dos mesmos com os alunos, permitiu uma formação mais dialogada entre o conhecimento acadêmico e o conhecimento escolar, além de propiciar um debate construtivo e a troca de conhecimentos entre os agentes envolvidos.

Metodologicamente, a proposta central da atividade, de utilizar o cinema em sala de aula, mostrou-se importante em dois sentidos: primeiro na formação dos bolsistas envolvidos, especialmente os bolsistas graduandos, ao oferecer conhecimento teórico para a utilização de fontes alternativas não escritas, como o cinema, como recurso didático no ensino da História. E, em segundo lugar, para atingir o ponto central do projeto que era aumentar o interesse dos alunos pelo estudo dessa disciplina. Objetivo esse que se mostrou realizado na participação ampla dos alunos nos filmes e nos debates.

No que diz respeito à relação entre a teoria e a prática, não significa que a atividade tenha sido realizada exatamente como planejada, mas que a reflexão, estudo e planejamento feitos antes da oficina contribuíram para uma atividade mais qualitativa, pois os atores envolvidos estavam seguros e preparados para participar da oficina. Inclusive, consideramos que as modificações que a oficina sofreu durante sua execução são o retrato de uma prática pedagógica dialética e dialogada que ouviu as demandas dos 
alunos, incorporou suas agências e respeitou a cultura escolar ao encarar a escola como espaço de experiência e produção.

Entendemos que a relação entre a teoria e a prática é um movimento dialético, e não estático, em que a teoria, em contato com a realidade, sofre alteração, da mesma forma que a prática também modifica a teoria criando um ambiente baseado na troca e no constante crescimento.

Para Nóvoa (2010), a educação passa por uma crise marcada pelo excesso de discursos e pobrezas de práticas. Nesse sentido, é necessário que a universidade valorize a escola, incentivando a formação dos novos docentes construída dentro da atuação profissional. Esse espaço de interação e formação mútua, no qual o diálogo entre escola e universidade ocorrem, é denominado pelo estudioso de casa comum (informação verbal) $)^{5}$. Dessa forma, afirmamos pela nossa experiência que o PIBID contribui para a formação dessa casa comum ao atuar na formação de professores dentro da profissão, baseando-se na aquisição de uma cultura profissional e concedendo aos profissionais mais experientes um papel central na formação dos mais jovens.

\section{Referências}

A VOZ da arquibancada. Direção: Bernardo Buarque de Hollanda, Jimmy Medeiros, Bernardo Bortolloti e Rosana da Câmara Teixeira, Produção: Núcleo de Audiovisual e Documentário CPDOC/FGV. Rio de Janeiro, Brasil, 2014. Disponível em < http://cpdoc.fgv.br/nucleoAD/producoes >

BRASIL, Ministério da Educação. Coordenação de Aperfeiçoamento de Pessoal de Nível Superior. Diretoria de Formação de Professores da Educação Básica. Relatório de Gestão PIBID 2009-2013. Brasília, 2013. Brasil.

CARDOSO, Ciro Flamarion; MAUAD, Ana Maria. História e Imagem: os exemplos da fotografia e do cinema. In. CARDOSO, Ciro F.; VAINFAS, Ronaldo. Domínios da história: ensaios de teoria e metodologia. Rio de Janeiro, Campus, 1997.

\footnotetext{
${ }^{5}$ Conteúdo fornecido durante as aulas abertas que o professor António Nóvoa ofereceu na Faculdade de Educação da UFRJ, organizado pelo Programa de Pós-Graduação em Educação (PPGE).
} 
GATTI, Bernadete A.; ANDRÉ, Marli E. D. A.; GIMENES, Nelson A. S.; FERRAGUT, Laurizete. Um estudo avaliativo do Programa Institucional de Bolsas de Iniciação à Docência (PIBID). São Paulo: FCC/SEP, 2014

GATTI, Bernadete A.; ANDRÉ, Marli E. D. A.; GIMENES, Nelson A. S.; FERRAGUT, Laurizete; NUNES, M. (Orgs.) Formação de professores para o ensino fundamental: estudo de currículo das licenciaturas em pedagogia, língua portuguesa, matemática e ciências biológicas. São Paulo: FCC, 2009

GERAL. Direção e Produção: Anna Azevedo. Rio de Janeiro, Brasil, 2010. Disponível em: <https://vimeo.com/15779807>

HARTOG, François. Regimes de historicidade. [Time, History and the writing of History KVHAA Konferenser 37: 95-113 Stockholm 1996]. Disponível em: <http//www.fflch.usp;Br/dh/heros/excerpta/hartog.html>. Acesso em 20/07/2016.

KNAUSS, Paulo. O desafio de fazer História com imagens: arte e cultura visual. ArtCultura, Uberlândia, v. 8, n. 12, p. 97-11, jan-jun., 2006.

KOSSOY, Boris. Fotografia \& história. São Paulo: Ateliê Editorial, 2001. Edição revista.

MENESES, Ulpiano T. Bezerra de. Fontes visuais, cultura visual, História visual. Balanço provisório, propostas cautelares. Revista Brasileira de História, v. 23, n. 45, jul., 2003.

MENESES, Ulpiano T. Bezerra de. Rumo a uma "história visual", In: MARTINS, José de Souza; ECKERT, Cornélia; NOVAES, Sylvia Caiuby (Orgs.), O imaginário e o poético nas ciências sociais. Bauru: EDUSC, 2005, cap. 2

NÓVOA, Antonio. Para uma formação de professores construída dentro da profissão. Revista Educación, $2010 \quad$ - $\quad$ ince.mec.es. Disponível em: <http://www.revistaeducacion.mec.es|re350|re350_o9por.pdf>

SONHOS Tropicais. Direção e Produção: André Sturm. Brasil, 2001, DVD

5X FAVELA: agora por nós mesmos. Direção: Cacau Amaral, Cadu Barcelos, Luciana Bezerra, Luciano Vidigal, Manaira Carneiro, Rodrigo Felha, Wagner Novais. Produção: Globo Filmes. Rio de Janeiro, Brasil, 2010, DVD. 
Recebido em: 31/07/2016 Aprovado em: 08/11/2016

Universidade do Estado de Santa Catarina - UDESC Centro de Ciências Humanas e da Educação - FAED

Revista PerCursos

Volume 17 - Número 35 - Ano 2016 revistapercursos@gmail.com 